\title{
Electron Microscopic Studies on the Development of the Thyroid Gland of the Chick Embryo
}

\author{
By
}

\author{
Hisao FUJITA, Mitsuo MAGHINO and Shiro NAGATA \\ Department of Anatomy, Kyoto Prefectural University of Medicine \\ (Kyoto Furitsu Ika Daigaku), Kawaramachi, Kamikyoku, Kyoto, Japan
}

Though numerous electron microscopic studies of the thyroid gland have already been published since the works of MONROE (1953) and BRAUNSTEINER et al. (1953), many questions are still remained to be answered as to the secretory phenomena in this organ. To answer the following three questions, the present study was carried out: First, what intracellular structure is differentiated in the secretory cell when the embryonal thyroid gland first begins to produce a colloid? Secondly, how is the intracellular granule manufactured in the epithelial cell? Thirdly, what is the mechanism of a follicle formation?

\section{Materials and Methods}

About eighty white-Leghorn chick embryos of 7, 8, 9, 10,11, 12, 13, 14, 15, 16, 19 and 20 days of incubation were used in this study. Some of their thyroid glands were fixed in $1 \%$ osmium tetroxide buffered $\mathrm{pH} 7.35$ with phosphate. After fixation, the tissues were dehydrated with alcohol and embedded in a mixture of 4 parts of n-butyland 1 part of methyl-methacrylate. Sections were cut with J. U.M. 4 type ultramicrotome and observed with the J.E.M. 4A type electron microscope. Some other thyroid tissue samples were fixed in BouiN's solution, embedded in paraffin, cut at $6 \mu$ and stained with hematoxylin-eosin and by the periodic acid-Schiff method.

\section{Observations}

By light microscopy, the thyroidal colloid follicles stained purple in periodic acidSchiff stain appear in the epithelial cell cords of the gland at 9 days of incubation in one third of the whole cases, while at 10 days in all the other embryos, as reported by FUJITA and NAGATA (1962).

By the electron microscopic observation, the epithelial cells one or two days before colloid formation contain some mitochondria with lamellar cristae, small particles distributed throughout the cytoplasm, and small GoLGI fields consisting mainly of GOLGI vesicles. However, GOLGI vacuoles and rough- and smooth-surfaced endoplasmic reticulum are not distinct (Fig. 1). At 9 or 10 days of incubation, when the colloid follicles appear, the rough- and smooth-surfaced endoplasmic reticulum is developed suddenly 
(Fig. 2). These cytoplasmic vacuoles become larger in number and size with increase of embryonic days (Fig. 3, 4, 5). FELDMAN et al. (1961) reported similar findings in the thyroid gland of rat embryos. Some mitochondria are quite near the outer surface of the rough- and smooth-surfaced endoplasmic reticulum (Fig. 4).

There are two kinds of granules, light and dense, in the thyroidal epithelial cell of the chick embryo (Fig. 6), as also reported by EKHOLM and SJÖSTRAND (1957) and YOSHIMURA and IRIE (1959) in some adult animals.

The intracellular granules of low density are $0.2-2.5 \mu$ in diameter, and are present at a time when the endoplasmic reticulum appears. The internal density of this granule is similar to the cisternae of rough-surfaced endoplasmic reticulum and to the follicular colloid. Sometimes the limiting membrane of this granule is continuous with that of the rough-surfaced endoplasmic reticulum (Fig. 7).

Mitochondria, being often quite near the outer surface of the rough-surfaced endoplasmic reticulum, might play also a role in the formation of the droplet (Fig. 4).

The second type of granule with high electron density is $0.2-0.5 \mu$ in diameter when it appears in the 8-10 day-old chick embryos. After a few days, some of these dark granules enlarge to about $0.2-1.5 \mu$. In the GOLGI region, some vesicles of $0.2-0.4 \mu$ in diameter are filled with a dark homogeneous substance similar to the dense granule described above (Fig. 8). Mitochondria are often stituated near the Golgr field. These phenomena suggest that the dense granules are formed in the GoLGi field, especially in the GOLGI vesicles, and that mitochonsria are also necessary for the granule formation.

Concerning the early formation of the follicle lumen, two mechanisms are observed (Fig. 9). One of these was reported in a previous paper by FUJITA and MAGHINO (1961). As the intracellular droplet of the low density appearing at 9-10 days of incubation enlarges, it approaches the cell membrane and comes in contact with another droplet in the adjacent cell. Then, by fusion and disappearance of the cellular and colloidal limiting membrane at the contact point, these droplets fuse each other (Fig. 9a). This simplest follicle lumen grows larger and larger through repeated fusing with other cellular colloid droplets, finally becoming a typical follicle. Details of this hypothesis have already been published in an earlier paper (1961). However, sometimes in the 9-10 day-old chick embryo, we observed a narrow intercellular space and a interdigitation of the epithelial cell membrane with the adjacent cell border, and the electron density of this space was much less than that of the colloid follicle (Fig. 1).

This empty-appearing intercellular space may later become a follicular lumen containing a colloid by the secretion of the droplet from the epithelial cell (Fig. 9b).

The follicular lumen of the early functional stage of the gland has a few microvilli projecting from the cell surface to the lumen. The desmosome is also seen in the simplest follicle consisting of only two cells. As late as 20 days of incubation, we could not find any apocrine secretory projection on the cell surface except for a few microvilli. 
In a few cells of 19 and 20 day-old embryos, we sometimes observed a few microvilli containing a droplet of low density as HERMAN (1960) reported in TSH-treated salamanders.

The pericapillary region of the gland at approximately 15 days of incubation does not consist of two basement membranes and of pericapillary space between them. A very thin basement membrane of about 100-300 $\AA$, homogeneous and dense, is only seen between endothelium and epithelial cell (Fig. 10).

\section{Discussion}

On the granular formation of the thyroid gland, by light microscopy, TAKAGI (1922) reported that the secretory granules are transformed from the mitochondria, while OKKELS (1934) presumed that these were not transformed from mitochondria, but made in the mitochondrial contact region by the condensation activity of this organells. By electron microscopy, DEMPSEY and PETERSOn (1955), FUJITA et al. (1958) and WANG (1958) suggested that the thyroidal colloid droplet might be accumulated and produced in the ergastoplasmic sac or the endoplasmic reticulum. This droplet corresponds to that of low density of EKHOLM and SJÖSTRAND (1957), and their term "ergastoplasmic sac" and "endoplasmic reticulum" refers to "rough-surfaced endoplasmic reticulum." On the other hand, WATARI et al. (1961) has the opinion that the granule of low density comes from mitochondria. But the distinct finding which proves these hypothesis clearly has not yet been reported. STOLL et al. (1957) speculated a great role of the cytoplasmic vacuole on the colloid formation in the chick embryos.

In the present study, three findings were obtained as follows; (1) Rough- and smooth-surfaced endoplasmic reticulum appears on the same day when the intracellular colloid droplet and the follicular colloid are first observed. (2) The limiting membrane of this droplet is continuous with the rough-surfaced endoplasmic reticulum. (3) The internal electron densities of the follicular lumen and of the intracellular droplet of low density are quite similar to those of the rough-surfaced endoplasmic reticulum.

From these facts, it is concluded that the intracellular droplet of low density is sure to be produced in the cisternae of the rough-surfaced endoplasmic reticulum, and that the relationship between the droplet and smooth-surfaced endoplasmic reticulum is obscure. The RNP particles on the outer surface of the rough-surfaced endoplasmic reticulum might be necessary to produce the thyroglobulin. However, as the all vacuole systems including the rough- and smooth-surfaced endoplasmic reticulum and GOLGI vacuoles become distinct at the same time when the colloid begins to be formed, the relationship between smooth-surfaced endoplasmic reticulum and intracellular droplet of low density is also considered to be very intimate. Mitochondria are very often situated near the outer surface of the rough-surfaced endoplasmic reticulum, as reported by ICHIKAWA and IRIE (1957) and FUJITA et al. (1958). Though the necessity of this organelle in producing the droplet is suggested from this phenomena, the mitochondrial transformation into the granule is not recognized in this gland. 
The other granule of high density is formed in the GOLGI field, as suggested by HERMAN (1960) in the salamander thyroid. The mitochondria situated near the GOLGI field might play a role to make this granule. However, the difference in chemical properties of these two kinds of granules is now unanswered and should be studied in the future.

Though the pericapillary region of the adult thyroid gland consists of the two layers of basement membranes and the pericapillary space between them, this structure is not distinct before 15 days of incubation. The typical pericapillary structure described above becomes clear with the increase of days. The hormonal secretion into the blood vessel might be very little in the embryonic days and it becomes more and more day by day. This suggests that the development of the pericapillary structure is very intimate with the hormonal secretion.

\section{Summary}

Thyroid glands of chick embryos from 7 to 20 days of incubation were studied with the electron microscope. In 7,8 or 9 day-old embryos in which a colloid is not yet formed, the vacuole systems are not well developed in the epithelial cell. A few mitochondria, PALADE's particles and small GOLGI fields without large vacuoles are distributed throughout the whole cytoplasm of the secretory cell.

At 9-10 days when colloid-containing follicles and intracellular droplets of low density appear in the epithelial cell cords, the rough- and smooth-surfaced endoplasmic reticulum also becomes distinct. Sometimes the limiting membrane of this droplet continues with the rough-surfaced endoplasmic reticulum. This suggests that the granule of low density is produced in the rough-surfaced end plasmic reticulum. Mitochondria observed near the outer surface of this reticulum might have also some function in manufacturing this droplet. On the other hand, the granule of high density is produced in the GOLGI vesicles. A typical apocrine secretory process is not observed in the embryonic thyroid of the chick.

Some of the colloid-containing follicles are produced by fusing of the intracellular colloid of one cell and that of an adjacent cell, while others are originated from the intercellular space.

A typical pericapillary structure consisting of two layers of basement membranes and pericapillary space between them is not distinct before 15 days of incubation.

\section{References}

BRAUNSTEINER, H., H.K. FELLINGER and F. PAKESCH : Endocrinology, 53 : 122-133, (1953).

DEMPSEY, E.W. and R.R. PETERSON : Endocrinology, $56: 46-58$, (1958).

EKHOLM, R. and F.S. SJÖSTRAND : J. Ultrast. Res., 1 : 178-199, (1957).

FELDMAN, J.D., J.J. VAZQUEZ and S.M. KURTZ : J. Biophys. Biochem. Cytol., 11 : 365-3.84, (1961). FUJITA, H., M. KANO and S. OKAMOTO : Arch. Hist. Jap., 14 : 61-78, (1958). 


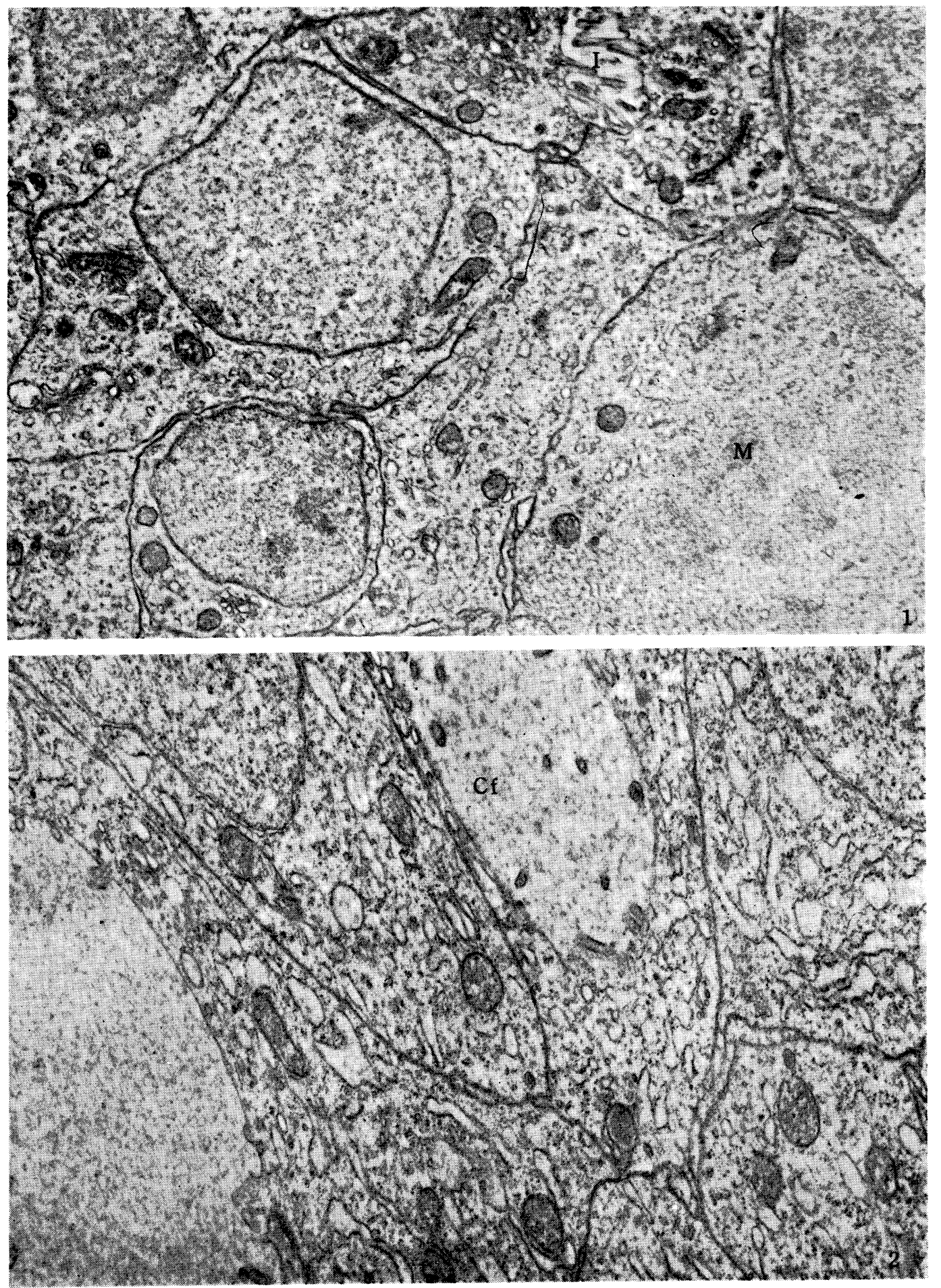




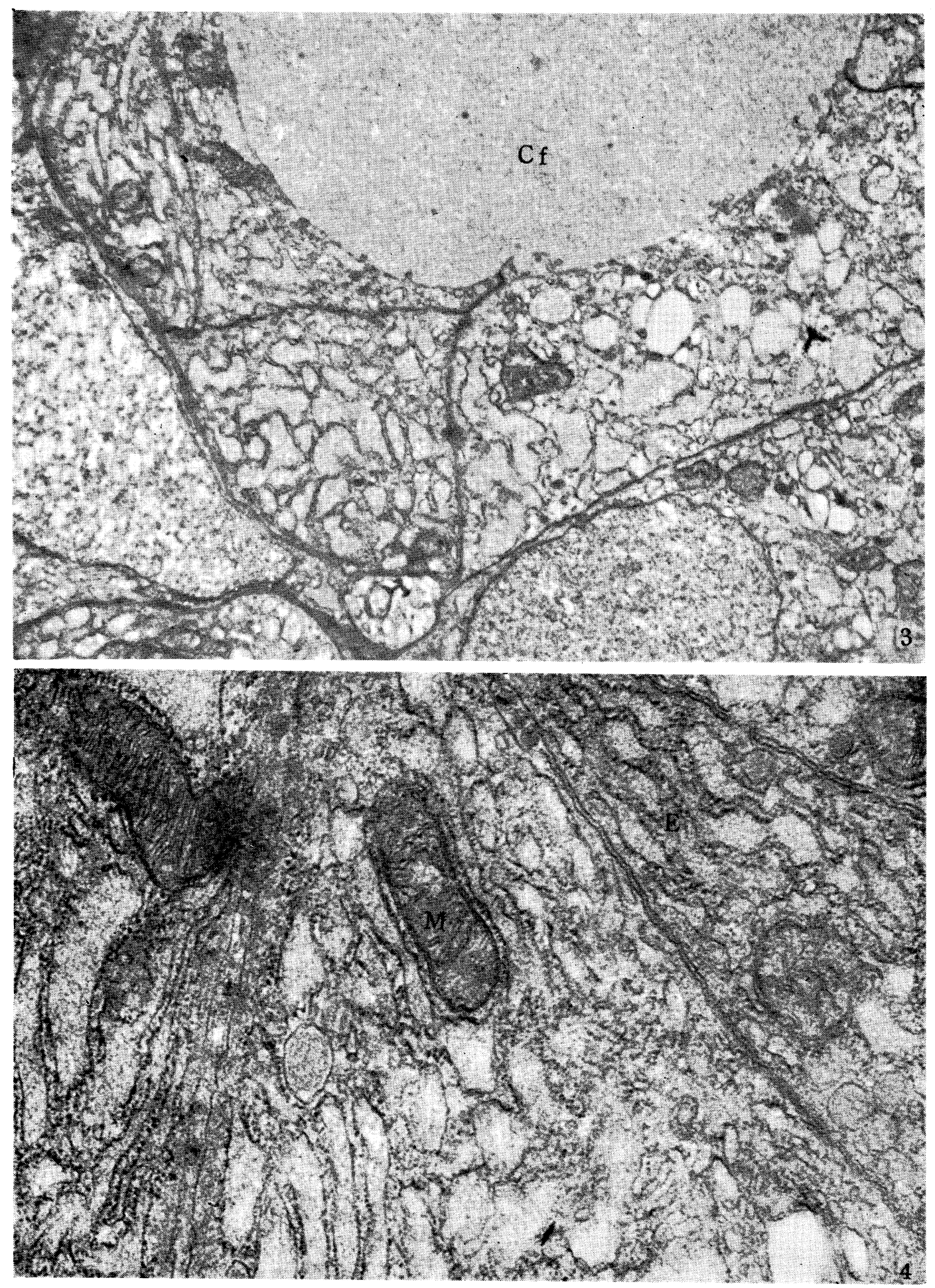




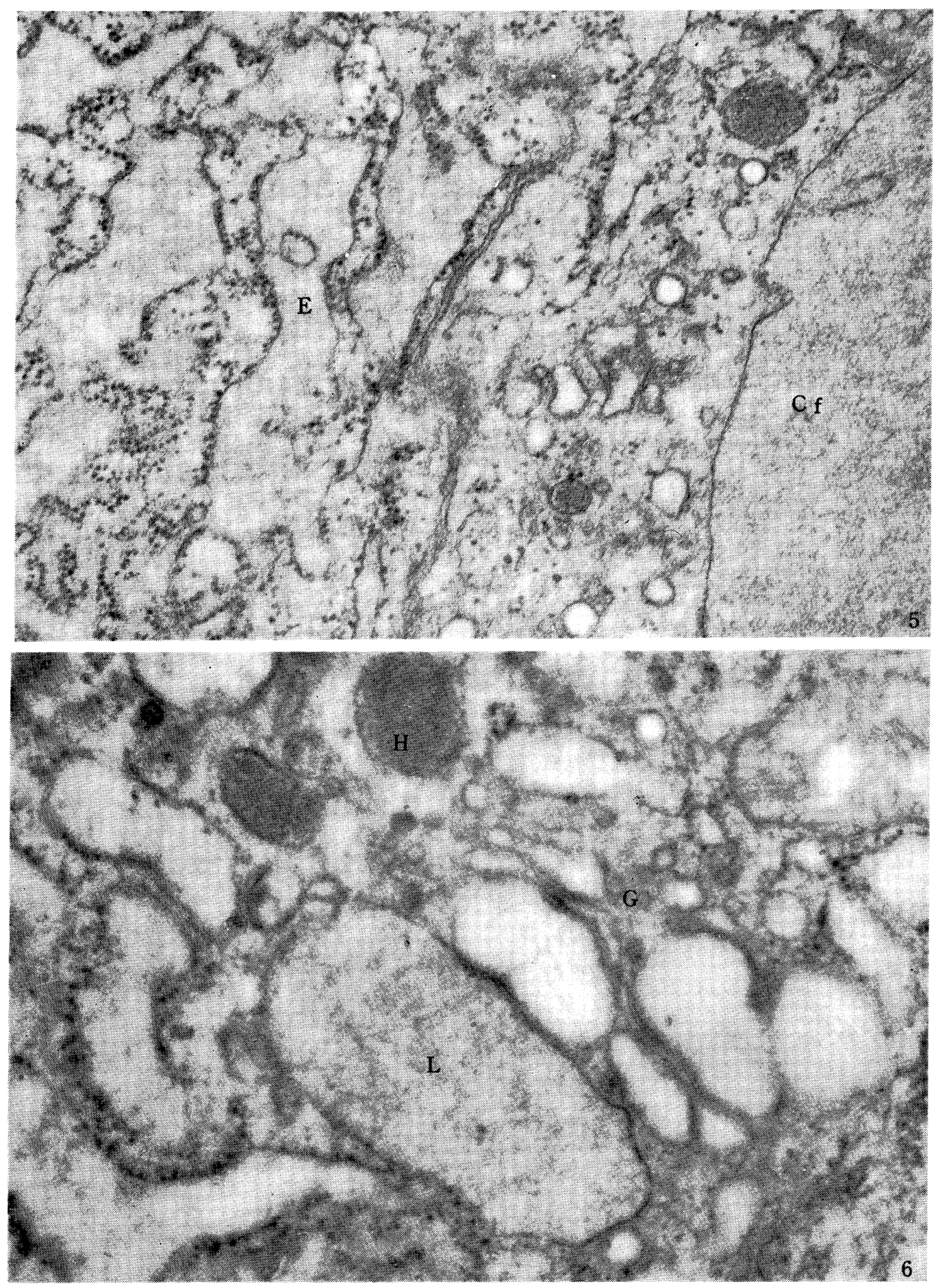




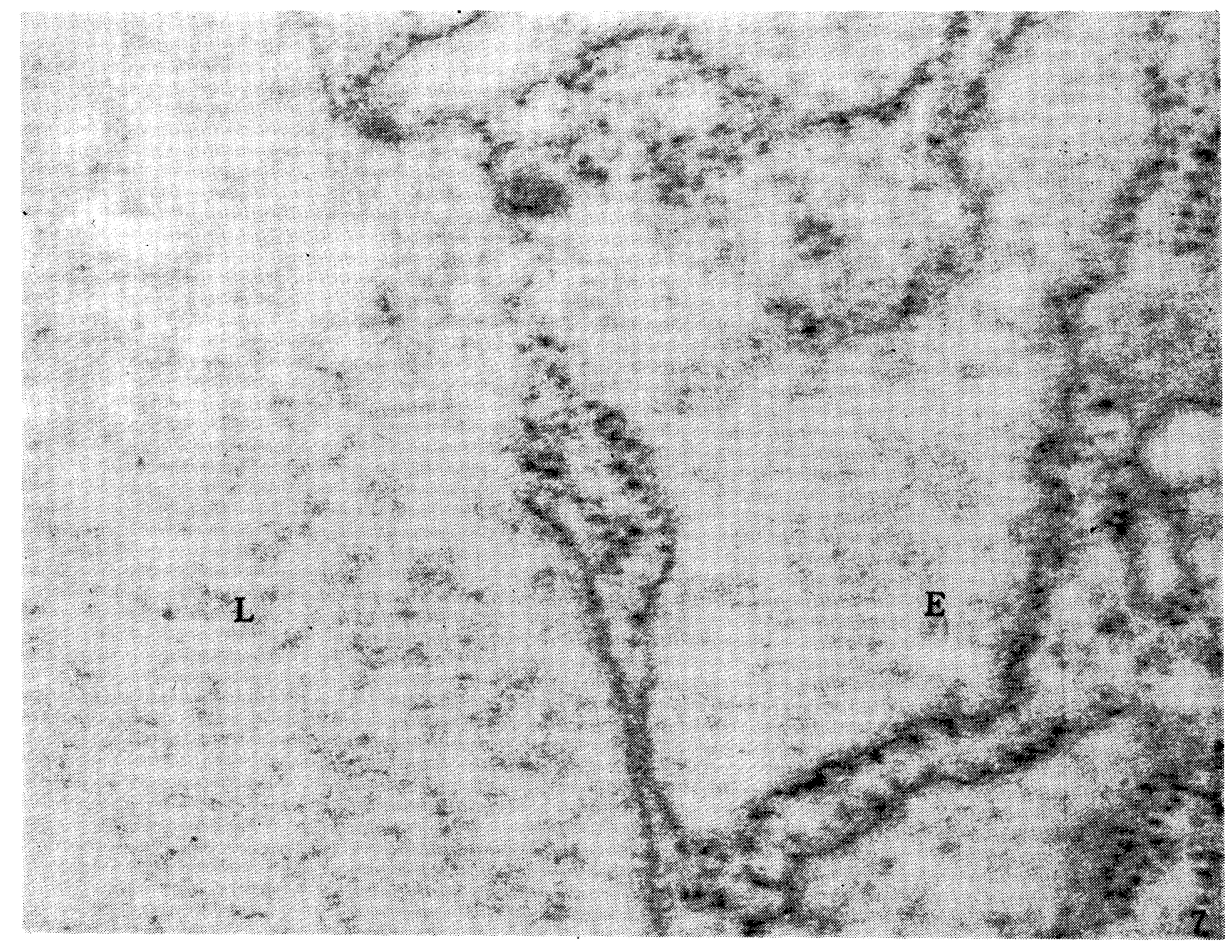

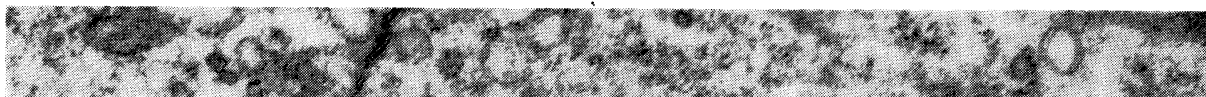

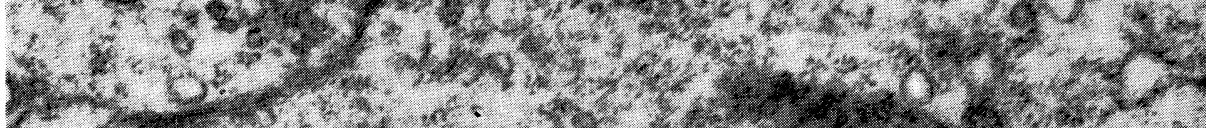

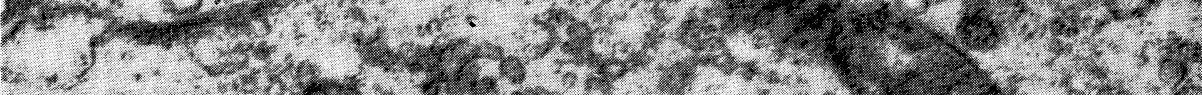

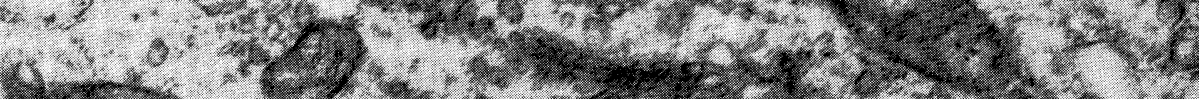

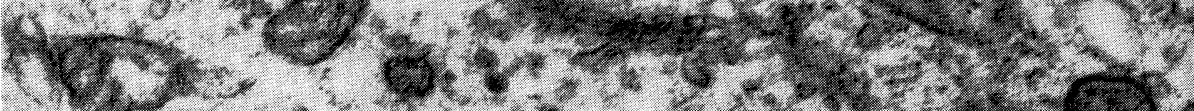

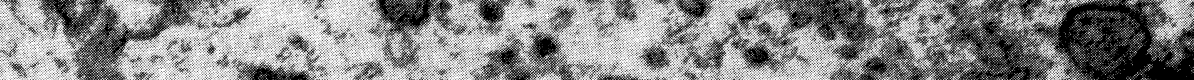

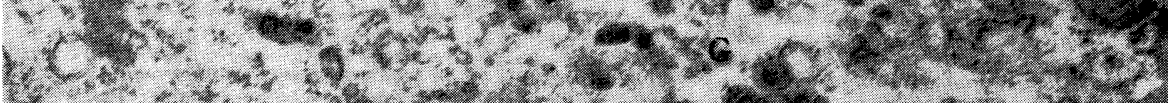

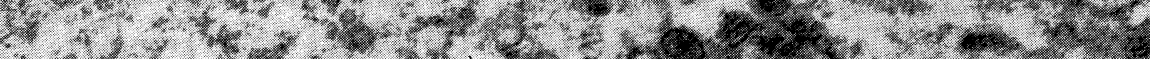

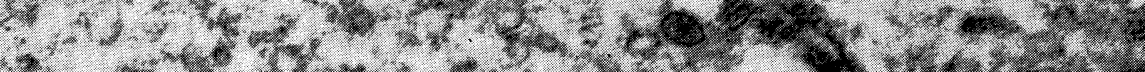

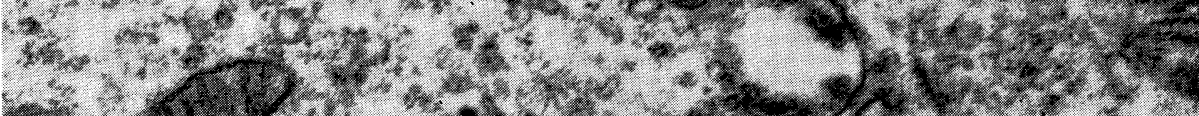

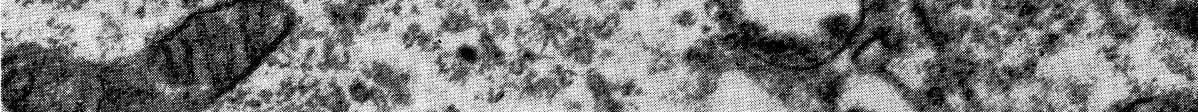

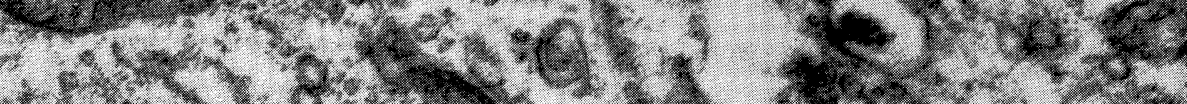
(2)

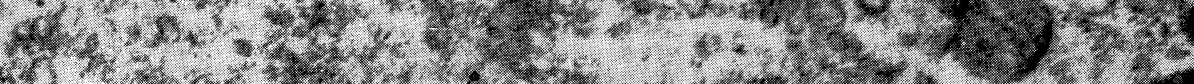

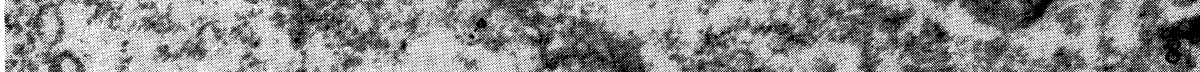




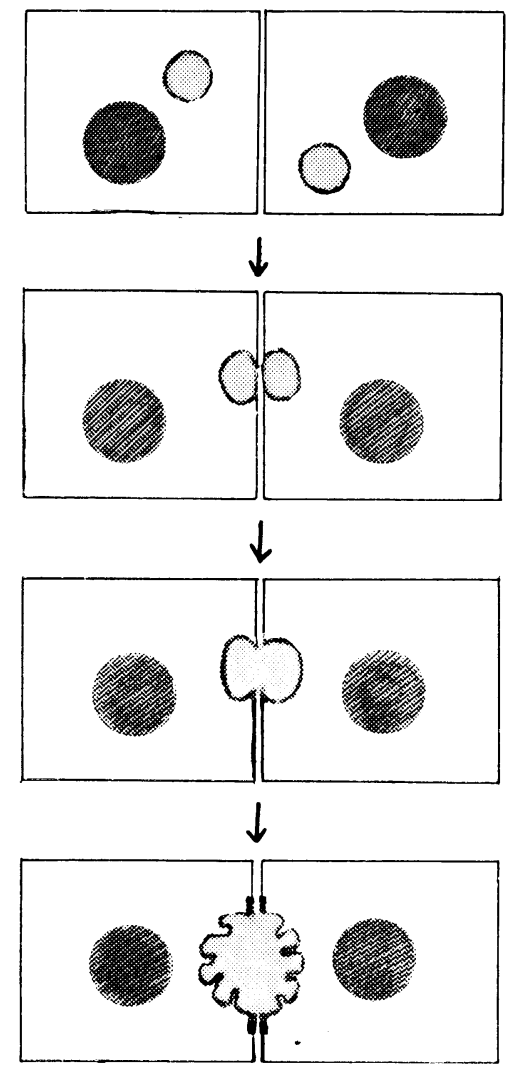

(a)

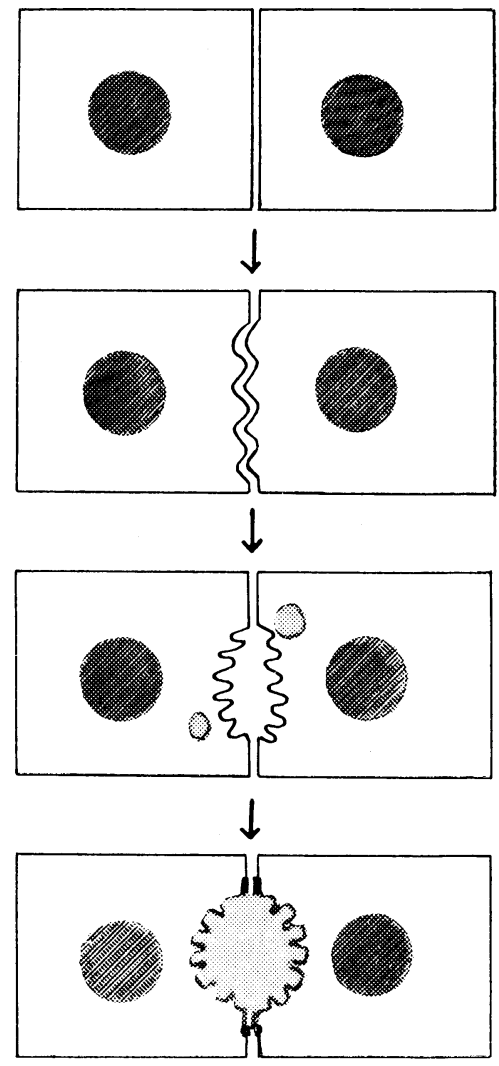

(b)

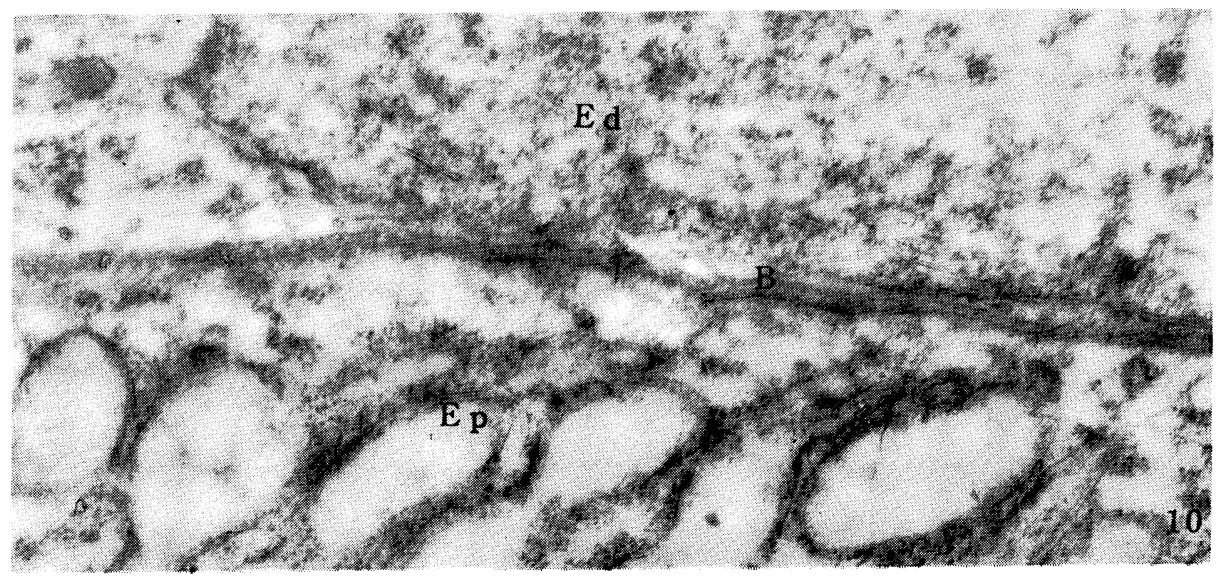


FUJITA, H. and M. MACHINO : Exp. Cell Res., 25 : 204-207, (1961).

FUJITA, H. and S. NAGATA : Arch. Hist. Jap. 22 : 187-191, (1962).

HERMAN, L. : J. Biophys. Biochem. Cytol., $7: 143$ 150, (1960).

ICHIKAWA, A. and M. IRIE : Acta Anat. Nipponica, 32 : 93-94, (1957).

IRIE, M. : Arch. Hist. Jap., 19 : 39-74, (1960).

MONROE, B.G. : Anat. Rec., $116: 345-362$, (1953).

OKKELS, H. : Arch. Exper. Zellforsch., $15: 343$, (1934).

STOLL, R., P. BLANQUET, A.P. LACHAPÈLE, R. MARAUD and A. MAGIMEL : Proc. Stockholm

Conf. Electron Microscopy, 173-175. Almqvist and Wiksell, Stockholm. (1957).

TAKAGI, K. : Fol. Anat. Jap., $1: 69$, (1922).

WANG, L. : Denshi-Kenbikyo (Tokyo), $6: 184-191$, (1958).

WATARI, N. and M. SEKINE : Acta Anat. Nipponica. $36: 367$, (1961).

WISSIG, S.L. : J. Biophys. Biochem. Gytol., $7: 419-432$, (1960).

YOSHIMURA, F. and M. IRIE : Hormon to Rinsho (Tokyo), $7: 367-394$, (1959).

\section{Explanation of figure}

Fig. 1. A thyroid gland of 9 day-old chick embryo without typical colloid follicle. The endoplasmic reticulum and the Golgi vacuoles are not distinct in the epithelial cell. A small intercellular space (I) which might become a follicular lumen is seen. A cell in mitosis (M) is present $(\times 15000)$

Fig. 2. A thyroid gland of 10 day-old chick embryo. Two colloid follicles (Cf) are seen. In the epithelial cell, the endoplasmic reticulum is well developed comparing with Fig. 1. $(\times 20000)$

Fig. 3. A thyroid gland of 16 day-old chick embryo. Well developed cytoplasmic vacuoles are noticed. (Cf) : Colloid follicle. $(\times 7500)$

Fig. 4. Rough-surfaced endoplasmic reticulm $(\mathrm{E})$ and mitochondria $(\mathrm{M})$ in the thyroid epithelial cell of a 16 day-old chick embryo. $(\times 39000)$

Fig. 5. A thyroid epithelial cell of 20 day-old chick embryo. Rough-surfaced endoplasmic reticulum $(\mathrm{E})$ is well developed. (Gf) : Colloid follicle. $(\times 48000)$

Fig. 6. A thyroid epithelial cell of 20 day-old chick embryo. Two kinds of intracellular droplets, of low $(\mathbf{L})$ and high $(\mathbf{H})$ density are seen. Small granules of high density are seen in the GoLGI field $(\mathrm{G})$. GV : GoLGI vacuoles. $(\times 70000)$

Fig. 7. A thyroid epithelial cell of 20 day-old chick embryo. Continuation of the rough-surfaced endoplasmic reticulum $(\mathrm{E})$ and the limiting membrane of the intracellular droplet of low density $(\mathrm{L})$ is seen. $(\times 75000)$

Fig. 8. Dense granule formation in the Golgr field $(G)$ of the epithelial cell 8 days after incubation. $(\times 31200)$

Fig. 9. Two formulae of follicle formation.

Fig. 10. A endothelial cell (Ed), a basal part of the epithelial cell (Ep) and a thin basement membrane (B) between them. Nine day-old chick embryo, two days after injection of 10 units of T.S.H. $(\times 48000)$. 